\title{
Historia económica mundial 1870-1950
}

Global Economic History 1870-1950

Abraham Aparicio Cabrera* :

\begin{abstract}
Resumen
Este artículo revisa los hechos económicos más importantes sucedidos entre 1870 y 1950 a nivel mundial. El artículo aborda aproximadamente la mitad de los temas del segundo curso de la asignatura Historia Económica General que se imparte en la licenciatura escolarizada en la Facultad de Economía de la UNAM, conforme al Plan de Estudios vigente (1994).
\end{abstract}

Palabras clave:

- Historia económica

- Economia Internacional
Abstract

This paper reviews the most important economic facts occurred between 1870 and 1950 around the world. The paper discusses about half of the subjects of second course of General Economic History imparted at Faculty of Economics at UNAM, under current program of study (1994).

\section{Keywords:}

- Economic history

- International economy

JEL: N00, N10

\section{Introducción}

$\mathrm{E}$ n dos artículos anteriores (Aparicio, 2011; y Aparicio, 2013) se abordaron los principales temas del primer curso de la asignatura Historia Económica General que se imparte en la licenciatura en economía de la Facultad de Economía de la UNAM, conforme al plan de estudios vigente (1994). En este artículo se presentan los hechos económicos más importantes sucedidos entre 1870 y 1950 con lo cual se cubre el estudio de aproximadamente la mitad de los temas que integran el segundo curso de dicha asignatura.

\section{La economía mundial entre 1870 y $1913^{1}$}

Los calificativos de Gran Depresión o Depresión de los Precios y de Bella Época se dieron, respectivamente, a la crisis económica que experimentaron los países más desarrollados entre 1875 y 1890, y al posterior auge que duró hasta el inicio de la primera guerra mundial.

\section{La depresión de los precios}

Después de 1873 el comercio internacional continuó aumentando de manera importante pero lo hacía a un ritmo menos vertiginoso que antes, lo que realmente resultó preocupante era la depresión de los precios, es decir, la deflación

* Profesor de la Facultad de Economía de la UNAM.

${ }^{1}$ Hobsbawm (1998: 34-56, y 56-84). 
que redujo la rentabilidad de las empresas ${ }^{2}$. Entre los factores que explican la deflación el principal es la escasez relativa de oro; y entre las medidas que tomaron los países desarrollados para hacerle frente, las más representativas fueron la sustitución del patrón oro por un patrón bimetálico, ${ }^{3}$ la implementación de tarifas proteccionistas y, por supuesto, la actividad imperialista.

Se llamó imperialismo al periodo histórico entre 1875 y 1914 porque fue cuando, en la historia moderna, hubo mayor número de gobernantes que se autotitulaban oficialmente "emperadores", siendo el Reino Unido el principal protagonista, pues su supremacía económica siempre estuvo ligada a su acceso a los mercados y materias primas de sus colonias de ultramar, a finales del siglo XIX, una cuarta parte de la superficie del planeta se hallaba bajo la influencia oficial de la monarquía británica. Si incluimos su imperio informal (estados independientes), entonces una tercera parte del mundo era británico en un sentido económico. ${ }^{4}$

En su dimensión económica, el imperialismo actuó como un motor de la economía internacional que sirvió para escapar a las tendencias proteccionistas heredadas de la época de la "gran depresión de los precios". En 1987, el Primer Ministro británico decía al embajador de Francia en Londres:

"Si no fueran tan tenazmente proteccionistas... no nos encontrarían tan deseosos de anexionarnos territorios" ${ }^{5}$

Además, la presión del capital para conseguir inversiones más productivas, así como el deseo de colocar la producción excedente en nuevos mercados contribuyeron a impulsar la política de expansión, que incluía la conquista colonial.

\section{La "Bella Época"}

Una vez superada la depresión de los precios, las economías más desarrolladas experimentaron entre 1890 y 1914 una etapa de gran auge debido,

\footnotetext{
2 "En 1894 el precio del trigo era poco más de un tercio del de 1867... El precio del hierro cayó en un $50 \%$ entre 1871 y $1898 \ldots$ Los precios descendieron un $40 \%$ entre $1873-1896$ en el Reino Unido". (Hobsbawn, 1998: 44-45).

${ }^{3}$ En esta época hubo en Estados Unidos un gran debate monetario acerca de la plata, lo que dio origen al cuento del Mago de Oz. Véase Rockoff (1990).

4 "Entre 1876 y 1915, aproximadamente una cuarta parte de la superficie del planeta fue distribuida o redistribuida en forma de colonias entre media docena de estados... La mayor parte del mundo ajeno a Europa y al continente americano fue dividido en territorios que quedaron bajo el gobierno formal o dominio político informal de Reino Unido, Francia, Alemania, Italia, Países Bajos, Bélgica. En 1914, África pertenecía en su totalidad a los imperios británico, francés, alemán, belga, portugués y, de forma marginal, español. El continente americano fue una excepción, pues la dominación económica y política por parte de Estados Unidos de América se realizó sin una conquista formal" (Hobsbawn, 1998: 65-68).

${ }^{5}$ Hobsbawn (1998: 76).
} 
entre otros factores, al descubrimiento de enormes depósitos de oro en Sudáfrica, a la concentración de capital, a la gestión científica de la producción y de la organización empresarial, a una segunda revolución tecnológica, ${ }^{6} \mathrm{y}$ sobre todo al surgimiento del mercado de masas. El desarrollo de una gran mercado masivo de consumidores se debió al crecimiento de la población urbana de clase media -la tasa de crecimiento de la población europea pasó de 7\% en 1850 a 13\% entre 1900-1913-, el surgimiento de la venta a plazos de productos manufacturados de alto precio, y al surgimiento de nuevas industrias -como el cine que se desarrollaron espectacularmente entre 1895 y 1915. Debido a que $80 \%$ del mercado internacional era dominado por los consumidores de Europa y Estados Unidos, el comercio mundial tuvo un incremento notable en este periodo. ${ }^{7}$

También algunas economías en desarrollo, especialmente Argentina, lograron notables éxitos económicos, aunque su incipiente desarrollo económico estuvo ligado a aquellos sectores dedicados a la exportación de alimentos y de materias primas; y no debe olvidarse la importancia que tuvo para el auge de las economías más desarrolladas las importaciones de bienes manufacturados y de bienes de capital que hacían las naciones latinoamericanas. ${ }^{8}$

Así pues, previo al inicio de la primera guerra mundial la economía internacional había cambiado notablemente: el Reino Unido dejó de ser el único país totalmente industrializado; en 1913 Estados Unidos aportaban el 46\% de la producción industrial y minera mundial, Alemania 23.5\%, Reino Unido 19.5\% y Francia 11\%; en 1860 el 50\% de las exportaciones de África, Asia y América tenían como destino el Reino Unido, pero para 1900 ya sólo era el 25 por ciento. $^{9}$

\footnotetext{
6 "Como sabemos, fue en este periodo cuando se incorporaron a la vida moderna el teléfono y la telegrafía sin hilos, el fonógrafo y el cine, el automóvil y el aeroplano, y cuando se aplicaron a la vida doméstica la ciencia y la alta tecnología mediante artículos tales como la aspiradora y la aspirina” ... en Europa, entre 1880 y 1913 se construyeron tantos kilómetros de vías férreas como en el periodo conocido como 'la era del ferrocarril' 1850-1880" (Hobsbawn, 1998: 61).

7 "La marina mercante mundial, cuyo crecimiento indica aproximadamente la expansión de la economía global, permaneció más o menos invariable entre 1860 y 1890, fluctuando entre los 16 y 20 millones de toneladas. Pero entre 1890 y 1914, ese tonelaje casi se duplicó" (Hobsbawn, 1998: 58).

8 "El mercado internacional de materias primas se amplió extraordinariamente, entre 1880 y 1913 se triplicó el comercio internacional de esos productos, lo cual implicó también el desarrollo de las zonas dedicadas a su producción y su integración en el mercado mundial" (Hobsbawn, 1998: 59). La inserción de América Latina en el mercado mundial es ampliamente estudiada por Glade (2000).

${ }^{9}$ Hobsbawn (1998: 59).
} 


\section{La primera guerra mundial (1913-1919) ${ }^{10}$}

Objetivos económicos: el concepto de Mitteleuropa

En términos económicos, puede decirse que el principal objetivo que tuvieron los países beligerantes, en especial Alemania, era desmantelar la economía multilateral capitalista para sustituirla por las llamadas "grandes áreas económicas” que serían estructuradas a través del poder político. Al terminar las hostilidades, el orden económico liberal-capitalista estaba derrumbado, y la insistencia de las potencias vencedoras por restaurarlo tal y como estaba antes de la guerra retardó una década la recuperación de la economía mundial.

Puede decirse que el gobierno alemán asumió una postura moderada en cuanto a los objetivos de una eventual guerra, quería instaurar una Europa central unificada económicamente bajo su dominio:

La idea consiste en lograr la creación de una unión económica de la Europa central a través de acuerdos aduaneros... Esta unión debe instaurar la hegemonía de Alemania en Europa central, sin necesidad de recurrir necesariamente a un ejecutivo constitucional conjunto; en su seno sus miembros gozarían de una ostensible igualdad de derechos, pero estarían, de hecho, sometidos al liderazgo de Alemania. ${ }^{11}$

Estas pretensiones reclamaban la incorporación de algunos territorios de Francia y de Bélgica. La postura radical fue asumida por la Liga Panalemana, una asociación de extrema derecha en la que participaron algunos importantes terratenientes e industriales, la cual hizo una exitosa propaganda en la que sus intereses económicos resultaban ser los intereses de la nación (programa nacionalista), de tal forma que a finales de septiembre de 1914 la Liga organizó una asamblea en la que representantes de la industria, la agricultura, las artesanías, la banca y el comercio se pronunciaron por apoyar la política de expansión alemana. De manera concreta, la Liga quería una Europa central que, junto a los territorios que el imperio Alemán y Austria-Hungría obtendrían como botín de guerra, constituiría un amplio espacio económico uniforme.

Este objetivo quedó planteado en la doctrina de la Mitteleuropa (Europa Central), concepto económico que se originó en la Alemania imperial de la década de 1880. Para los políticos alemanes de la época era evidente que la expansión industrial del mundo exigía una "política imperialista", pero Alemania tenía serios problemas para realizar conquistas en ultramar, así 
que centró su interés en una Europa central bajo el gobierno de Alemania que debía constituir la base política y económica sobre la cual se apoyaría para hacer frente a la competencia de Estados Unidos, Gran Bretaña y Rusia. Así mismo, la doctrina del Lebensraum (espacio vital) para una población en proceso de crecimiento fue otro argumento que se esgrimió para convencer al gobierno en embarcarse en una "guerra preventiva" que aseguraría a Alemania una posición de predominio mundial partiendo de Europa central.

Es muy probable que, de haberse concretado la Mitteleuropa, ello hubiera sido contraproducente para Alemania, pues la famosa zona de Europa central únicamente absorbía 50\% de las exportaciones alemanas y solamente proveía $30 \%$ de sus importaciones, por lo cual la integración en la economía mundial ofrecía mejores oportunidades de crecimiento económico que un área protegida por el poder militar y las tarifas arancelarias. ${ }^{12}$ En suma, la Mitteleuropa no fue un programa económico, sino más bien una plataforma ideológica propuesta como alternativa a la supuesta inferioridad de Alemania en una económica mundial dominada por el imperialismo Inglés, y cuyo destino final sería el repliegue de Alemania hacia el proteccionismo y la autarquía.

\section{El Tratado de Versalles}

La guerra llegó a su fin con el Tratado de Versalles, el cual en materia económica resultó ser desastroso para la recuperación de la economía europea. En primer lugar, las potencias aliadas tenían intereses divergentes: Francia quería debilitar económicamente a Alemania y se concentró en la recuperación de Alsacia, Lorena y la cuenca del Sarre, cuyas minas de carbón eran codiciadas como deseable complemento al hierro de Lorena; Gran Bretaña, Italia y Rusia no querían un socio económico débil pues sus economías estaban íntimamente entrelazadas con las economías de las potencias centrales, como lo ejemplifica que $40 \%$ de las exportaciones rusas de cereales iban hacia Alemania. En segundo lugar, las nuevas fronteras geopolíticas significaron una reordenación de los recursos económicos que impusieron trabas al desarrollo de la economía europea e internacional (por la reordenación colonial) que se agravaron por las tendencias proteccionistas inmediatas. ${ }^{13}$

Pero la principal consecuencia de Versalles fueron las excesivas reparaciones de guerra impuestas a Alemania. La cifra final de reparaciones fue fijada en 132000 millones de marcos, y la cuestión de si Alemania podía pagar esa suma o si era económicamente viable, ni siquiera se discutió. De

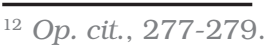

${ }^{13}$ Op. cit., 280-293. 
inicio, unos 20,000 millones de marcos oro se pagaron en especie con flota mercante, locomotoras, vagones de ferrocarril, maquinaria agrícola, ganado vacuno, caballos, carbón, colorantes. Además, el imperio alemán renunció a $13 \%$ de su territorio y a $10 \%$ de su población, perdió 15\% de sus áreas de cultivo, $75 \%$ del mineral de hierro y varios centros industriales. Las reparaciones de guerra recayeron en la práctica sobre Alemania porque era la única potencia central económicamente solvente, pero con ello se canceló cualquier posibilidad de una recuperación de su economía, y con ello, de la recuperación económica de Europa. ${ }^{14}$

\section{La economía mundial en el periodo entre guerras (1920-1939)}

El periodo entre las dos guerras mundiales tuvo su evento más significativo en la gran crisis económica de 1929-1932 y en el posterior New Deal para superar dicha crisis, pero también hubo otros hechos económicos relevantes como el surgimiento de Estados Unidos como la nueva económica líder en el mundo y su transcendental intervención a través del Plan Dawes para rescatar a las economías europeas del desastre provocado por los acuerdos de Versalles.

Estados Unidos como potencia hegemónica

Después de la primera Guerra Mundial, la importancia económica de Europa entró en una fase de declive debido, entre otros elementos, a que su producción industrial cayó 33\% entre 1913 y 1920. ${ }^{15}$ Esto abrió la puerta para que Estados Unidos, quedara como la única potencia económica que podía hacer frente al problema más urgente que era la escasez de alimentos en Europa, por lo que la American Relief Association facilitó alimentos por 1415 millones de dólares (mdd) a Europa. ${ }^{16}$

Las exportaciones totales de Estados Unidos pasaron de 2800 a 7300 mdd de 1913 a 1917; las exportaciones de trigo y harina de trigo pasaron de 125 a 505 mdd, las de carne de 68 a 668 mdd entre 1913 y 1918. Al interior de su economía, los Estados Unidos se vieron favorecidos por un auge en la industria pesada (hierro, acero, carbón, etc.) y la construcción de nuevas fábricas de armas y municiones. Se estima que la tasa de beneficio de las

${ }^{14}$ Idem.

15 Op. cit., 295.

${ }^{16}$ Ashworth (1978: 264). 
empresas pasó de 20 a 120\% de 1915 a 1918; y que en la agricultura los beneficios netos pasaron de 3900 a 8900 mdd entre 1913 y 1918. ${ }^{17}$

$\mathrm{El}$ auge la coyuntura de guerra hizo que Estados Unidos pasara de ser un país deudor a ser un país acreedor; sus inversiones en el exterior aumentaron 50\% entre 1914 y 1919, en tanto que las inversiones externas en territorio norteamericano cayeron de 7200 a 4000 mdd en el mismo periodo. Finalmente, no debemos olvidar que los gobiernos aliados le compraron a Estados Unidos diversas mercancías por un valor de 14200 mdd. ${ }^{18}$

América Latina y Japón también se beneficiaron del retiro del mercado mundial de la producción europea. Japón logró un fuerte incremento de sus exportaciones hacia los mercados asiáticos, pero el principal efecto positivo fue sobre su mercado interno, el cual se vio favorecido por la expansión de la industria del hierro y el acero, construcción de maquinaria, astilleros e industria química. América Latina, por su parte, aumentó sus exportaciones de alimentos y materias primas, y se benefició del aumento de los precios de sus productos en el mercado internacional, en cuanto a su mercado internó, los países más avanzados de la región comenzaron la sustitución de importaciones más como un respuesta a la coyuntura que como una política oficial para el desarrollo económico. ${ }^{19}$

\section{Las consecuencias de Versalles y el Plan Dawes}

Estados Unidos había adoptado una política aislacionista porque no quería jugar el papel de "proveedor" de los aliados, y menos que ellos llegaran a tener control sobre sus recursos naturales, además de que ideológicamente consideraba a la iniciativa privada libre de trabas como el instrumento más adecuado para hacer frente a las tareas de la reconstrucción. La principal preocupación de Estados Unidos era recuperar los préstamos (junto con los intereses devengados) que habían hecho a sus aliados durante la guerra, pues los consideraba como una transacción comercial ordinaria, sin embargo, esta postura cambió cuando se agudizaron los problemas económicos en Europa.

El principal obstáculo para la recuperación de la economía internacional era el problema de las deudas interaliadas. Estados Unidos había hecho préstamos 7100 mdd a sus aliados, ${ }^{20}$ siendo el Reino Unido su principal deudor; pero el Reino Unido, a su vez, prestó a los aliados el doble de lo que

\footnotetext{
${ }^{17}$ Hardach (1986: 299-303).

${ }^{18}$ Op. cit., 303.

${ }^{19}$ Op. cit., 307-311 у 316-323.

${ }^{20}$ Op. cit., 304.
} 
recibió de Estados Unidos, especialmente a Francia; éste último país esperaba recibir de Alemania las correspondientes reparaciones de guerra para que de ese modo iniciara el círculo de pagos. ${ }^{21}$

Sin embargo, las pésimas condiciones económicas en que había quedado Alemania le impedían hacer frente al pago de reparaciones de guerra, por lo que en julio de 1922 pidió una moratoria que Francia no aceptó, y a finales de ese año Alemania no pudo cumplir con los pagos acordados y en enero de 1923 Francia y Bélgica invadieron la cuenca del Ruhr creando nuevas movilizaciones militares. A esto hay que agregar que el Reino Unido cayó en una situación financiera insostenible porque pagaba a Estados Unidos más de lo que recibía por concepto de deudas aliadas y reparaciones de guerra. ${ }^{22}$

La economía alemana, por su parte, era un verdadero caos. El marco alemán se había devaluado 3 000\% entre 1919 y 1921, y para noviembre de 1923 un dólar se cotizaba en 4200 millones de marcos. La hiperinflación y el desempleo masivo colapsaron la economía de Alemania, lo que obligó a la reconsideración de toda la cuestión de las reparaciones de guerra. ${ }^{23}$

En septiembre de 1924, por iniciativa de los Estados Unidos, entró en vigor el Plan Dawes. El Plan ponía orden respecto a la cantidad que Alemania debía pagar por reparaciones de guerra: se pactó una reducción del monto total, se amplió el plazo de los pagos a 72 años, y los pagos anuales se elevarían gradualmente de 1000 hasta llegar a los 2500 millones de marcos en 1929. Además, se concedió a Alemania una "moratoria virtual" durante el primer año, pues los 800 millones de marcos que debía pagar fueron liquidados gracias a un préstamo multinacional sostenido básicamente por Estados Unidos. ${ }^{24}$

A diferencia de Versalles, donde se suponía que Alemania obtendría el dinero para el pago de las reparaciones de guerra mediante emisiones de bonos sin ninguna garantía, el Plan Dawes estableció claramente las fuentes de financiamiento sin asfixiar a la economía de Alemania: impuestos federales (50\%), impuesto sobre la renta bruta de los ferrocarriles (11.6\%), bonos garantizados con hipoteca sobre los bienes de capital de la industria (12\%) y bonos garantizados con hipoteca sobre los ferrocarriles (26.4\%). El Plan también aclaró la forma en la que debían distribuirse los pagos de reparaciones de guerra entre los aliados: Francia (52\%), Reino Unido (22\%), Italia (10\%), Bélgica $8 \%$, y otros países (8\%). ${ }^{25}$

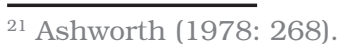

22 Op. cit., 267.

${ }^{23}$ Idem.

${ }^{24}$ Op. cit., 268-269.

${ }^{25}$ Op. cit., 269. 
Gracias a la puesta en marcha del Plan Dawes, hubo una mejora general de las condiciones monetarias de toda Europa: Alemania logró equilibrar su presupuesto y volvió al patrón oro a finales de 1924; la libra esterlina también regresó al patrón oro en 1925 con la paridad de preguerra respecto al dólar, ${ }^{26}$ y para ese año la producción en Europa volvió al nivel que tenía en 1913. En suma, el Plan Dawes fue una contribución útil para la mejoría de los aspectos económicos y políticos de las relaciones internacionales.

La “Gran Depresión” de 1929-1933

A penas se estaban disfrutando los efectos benéficos del Plan Dawes cuando sobrevino la peor crisis que ha vivido el capitalismo mundial en toda su historia. Conviene distinguir entre crisis financiera y crisis económica, la primera es una causa, entre otras, de la segunda.

\section{La crisis financiera}

Las causas principales de la crisis financiera fueron: una política de "dinero fácil" de la Reserva Federal otorgando créditos a una tasa de interés muy baja; la fragmentada estructura del sistema bancario; la estructura monopólica de los negocios (investment trusts y holdings companies) favorable a los fraudes de todo tipo; la falta de supervisión de las autoridades monetarias; y las declaraciones optimistas de influyentes hombres de negocios, banqueros ${ }^{27}$ y expertos ${ }^{28}$ que contribuyeron a incitar una especulación general y desenfrenada en el mercado de valores.

$\mathrm{El}$ incremento del precio de las acciones cotizadas en la bolsa de valores de Nueva York a partir de marzo de 1928 no se hallaba en relación con el aumento de los beneficios de las empresas, sino que era resultado de opera-

\footnotetext{
${ }^{26}$ Esta medida fue muy criticada por varios economistas de la época, especialmente John Maynard Keynes, quien argumentaba básicamente dos cosas: que los tipos de cambio fijados en el patrón oro no correspondían a los costos relativos y al poder adquisitivo de los países, lo que provocaba una sobrevaluación de la libra esterlina lo que perjudicaba las exportaciones inglesas; y que aunque la libra esterlina seguía siendo una moneda importante en el comercio internacional, el Reino Unido ya no tenía tanto oro para respaldar su moneda debido a la redistribución de las reservas mundiales de oro a favor de Estados Unidos. Véase Keynes (1923) y Keynes (1925).

${ }^{27}$ El presidente del Banco de la Reserva Federal de Nueva York, declaró en octubre de 1929:

"La situación industrial de los Estados Unidos es completamente sana... nada puede parar el alza de las cotizaciones... En general, la situación de los mercados es satisfactoria... las cotizaciones tienen una base sana dada la prosperidad de nuestro país" (Niveau, 1974: 183-184).

${ }^{28} \mathrm{El}$ connotado economista Irving Fischer declaró unos cuantos días antes del colapso financiero:

"Las cotizaciones de la Bolsa han alcanzado un alto nivel permanente... espero ver la Bolsa mucho más alta que hoy dentro de algunos meses” (Niveau, 1974: 184).
} 
ciones especulativas en las que los bancos obtenían enromes ganancias sin riesgo mediante el siguiente mecanismo: se pidieron créditos a los bancos para comprar acciones, a plazos muy cortos y a una tasa de interés muy elevada de $12 \%$; si esos créditos se pagan o no, no era motivo de preocupación para los bancos que incluso aceptaban de buena gana como garantía las mismas acciones compradas, porque los bancos recibían crédito de la Reserva Federal a una tasa de 5\%, lo cual les aseguraba, por la sola intermediación, una ganancia neta de 7 puntos porcentuales. Se estima que en junio de 1928 los préstamos para especular en la bolsa ascendían a unos 5,000 mdd y que para octubre de 1929 alcanzan los 7000 mdd. ${ }^{29}$

El desplome de la Bolsa comenzó el jueves 24 de octubre de 1929 cuando se pusieron a la venta 12.9 millones de acciones, y para el martes 29 de octubre se ofrecieron 33 millones de acciones que nadie compró. De octubre de 1929 a julio de 1933 el valor total del capital negociado en la Bolsa disminuyó 74000 mdd. ${ }^{30}$

\section{La crisis económica}

Con la crisis financiera sobrevino la crisis económica, primero en Estados Unidos y luego en la economía mundial. Entre 1929 y 1932, la producción industrial en Estados Unidos cayó alrededor de 50\%; la producción de maquinaria y equipo 75\%; la inversión privada pasó de 15800 a 900 mdd; quebraron 5096 pequeños bancos regionales; y en 1933 la tasa de desempleo era de 27\% afectando a 13 millones de personas. La deflación hizo su aparición: el nivel general de precios de la economía, para compras al mayoreo, cayó $28.2 \%$ y los precios de los productos agrícolas cayeron 58.7 por ciento. ${ }^{31}$

\section{Cuadro 1}

\section{Variación porcentual de la producción, 1929-1932}

\begin{tabular}{|l|c|c|}
\hline & PIB & Industria \\
\hline Estados Unidos & -44.7 & -28.0 \\
\hline Alemania & -40.8 & -15.7 \\
\hline Francia & -25.6 & -11.0 \\
\hline Reino Unido & -11.4 & -5.8 \\
\hline
\end{tabular}

Fuente: Niveau (1974).

\footnotetext{
${ }^{29}$ Niveau (1974: 182-185).

30 Op. cit., 184-185.

${ }^{31}$ Op. cit., 185-190.
} 
Estados Unidos alimentaba el comercio internacional con sus exportaciones de capitales, y con los cuantiosos préstamos que entre 1924 y 1929 otorgó a Alemania para que ese país pagara a Francia e Inglaterra lo acordado en el Plan Dawes, eran los recursos que hacían posible que Francia e Inglaterra también pagaran a Estados Unidos, y éste a su vez continuara prestando más dinero a Alemania.

Con la crisis económica en Estados Unidos el comercio internacional y el círculo de pagos se colapsó al secarse la fuente de recursos. Estados Unidos dejó de comprar materias primas, y Europa y América Latina dejaron de comprarle productos manufacturados. El sistema monetario internacional se derrumbó en 1931 cuando el Reino Unidos abandonó el patrón oro. A nivel mundial, la producción industrial cayó 37\% (Estados Unidos representaba $45 \%$ de la producción industrial mundial); el comercio internacional cayó $25 \%$ en volumen y $60 \%$ en valor. ${ }^{32}$

La crisis económica se profundizó por dos razones. En primer lugar, porque cada país trató de "exportar su desempleo" con medidas proteccionistas y devaluaciones competitivas ante el fracaso de la cooperación internacional. De 1927 a 1931, Alemania aumentó su tarifa sobre el valor de las importaciones de productos agrícolas de 27 a 83\%, Francia de 19 a 53\% e Italia de 25 a 66\%. En segundo lugar, porque los economistas liberales, que tenían considerable influencia en el mundo de los negocios, a pesar de la depresión continuaban proponiendo medidas ortodoxas basadas en una “moneda sana” y "un presupuesto equilibrado" por temor a la inflación. ${ }^{33}$

\section{El New Deal ${ }^{34}$}

Para salir de la crisis económica se aplicó, primero en Estados Unidos y luego en el resto de los países, una política económica de tipo heterodoxo basada en el pensamiento de economistas como John M. Keynes, que tenía por objetivo crear inflación y reactivar el crecimiento económico, teniendo como instrumento básico el aumento del gasto público financiado con emisión monetaria. Al conjunto de medidas concretas para salir de la crisis que fueron aplicadas por la administración del presidente Roosevelt se le conoció como New Deal.

En cuanto al valor del dólar se decidió: prohibir las exportaciones de oro, lograr una emisión monetaria sin contrapartida en oro, dar seguimiento a la devaluación del dólar respecto al oro y la acuñación ilimitada de moneda de

32 Op. cit., 194-199.

${ }^{33}$ Idem.

${ }^{34}$ Op. cit., 199-204. 
plata. En cuanto al sector financiero, se creó el seguro sobre los depósitos bancarios, y se impidieron los créditos para la especulación en la Bolsa.

Para provocar el alza de los precios se autorizó al gobierno la compra y el almacenamiento de la producción agrícola y la limitación de las cosechas; para incentivar la inversión se buscó un régimen más competitivo para las empresas; para reactivar el consumo se decretaron aumento de salarios y reducción de las horas de trabajo; y como medida fundamental se autorizó al gobierno a financiar obras públicas por 3,300 mdd, monto que después de elevó a 13000 mdd que se emplearon en la construcción de 122000 edificios públicos, más de un millón de kilómetros de carreteras, 77000 puentes, y 285 Aeropuertos.

El New Deal fue la primera gran experiencia de intervención estatal en la principal economía capitalista del mundo, tuvo sus efectos más sobresalientes en el terreno social, por la ayuda a los desempleados a través de las obras públicas (para 1938 se habían contratado 3.8 millones de desempleados). La conclusión es que si el gasto público no hubiese sustituido al gasto privado, seguramente la depresión hubiese sido todavía más grave o hubiera tomado más tiempo la recuperación.

\section{Segunda Guerra Mundial y reconstrucción}

La segunda guerra mundial tuvo sin duda muchas causas, pero en el ámbito económico puede decirse que los gobiernos de Alemania y Japón hicieron una elección deliberada del conflicto armado como instrumento de política, influidos por el convencimiento de que la guerra podría servirles para solucionar sus problemas económicos de más largo plazo. ${ }^{35}$ Antes del inicio de las hostilidades, el gobierno nacional socialista ya había elevado el gasto militar para el rearme como base de su política económica, e implementado el control de precios, salarios, comercio interno, comercio exterior, y tipo de cambio para mantener altos niveles de producción y de empleo, medidas que terminaron por aislar a Alemania de la economía internacional.

Objetivos económicos: el concepto de Grossraumwirtschaft ${ }^{36}$

El aislamiento de Alemania propició que resurgiera la antigua tesis de la Mitteleuropa, pero ahora con el nombre de Grossraumwirschaft (economía de las grandes áreas), doctrina que fue desarrollada no sólo desde la esfera po-

35 Milward (1986: 14-15).

${ }^{36}$ Op. cit., 19-29. 
lítica, sino también desde la esfera de los intelectuales. ${ }^{37}$ La tesis de la Grossraumwirtschaft buscaba un nuevo orden económico mundial de tipo autárquico, lo que justificaba una política expansionista. También se recurrió otra vez a la doctrina del Lebensraum (espacio vital) para buscar la ampliación del territorio de Alemania y conformar un área suficientemente grande para permitirle desempeñar su liderazgo económico en Europa; y también se usó como pretexto la lucha contra el comunismo, aunque el objetivo de quitar Ucrania a la Unión Soviética era más bien suministrarse materias primas.

La tesis de la Economía de las Grandes Áreas sostenía que la crisis mundial de 1929-33 había puesto punto final a la etapa de desarrollo económico basado en el capitalismo liberal y en el comercio internacional, por lo que la "era del Estado nacional" como unidad económica debía ser reemplazada por la "era de las grandes áreas geográfico-económicas". Estas grandes áreas proporcionarían un mercado más amplio que podía ser satisfecho, aún en una era de depresión, con sus propios recursos y potencial productivo (autarquía de la "gran área"); de esta manera el empleo y el ingreso ya no dependerían del comercio internacional, sino de la reordenación del mapa mundial en áreas económicas "naturales" de mayor tamaño, tal como se habían constituido los Estados Unidos y la Unión Soviética. Se suponía que Alemania, con algunos territorios conquistados, sería el centro manufacturero y de desarrollo de esta tercera gran área económica, en tanto que la periferia suministraría materias primas y alimentos.

A la luz de los argumentos anteriores, resulta comprensible que esta tesis atrajera la simpatía y el apoyo de ciertos círculos empresariales de Alemania que pensaban extender sus intereses hasta las nuevas fronteras del Reich (imperio), como IG Farben, un conglomerado químico, y Mansfeld, un grupo del ramo de los metales no férricos. Así mismo, la tesis recibió el apoyo de aquellos grupos sociales cansados de los vaivenes despiadados e incontrolables de la economía alemana vividos desde 1918. Finalmente, la tesis fue aderezada con ideas raciales que reclamaban una reconstrucción racial, política y económica de Europa.

\section{Efectos de la guerra y recuperación económica ${ }^{38}$}

Evidentemente, la guerra tuvo efectos nocivos sobre la economía mundial. Se habla de entre 45 y 50 millones de muertos, 42 millones de ellos en Europa y tan sólo en la Unión Soviética unos 20 millones; además de 37 Op. cit., 20 nota.

${ }^{38}$ Wee (1986: 15-43). 
4 millones de heridos graves e inválidos. El flujo migratorio, provocado por nuevas fronteras, ahondó la escasez de alimentos y para evitar una crisis humanitaria de grandes proporciones en Europa, Estados Unidos proporcionaron alimentos a Europa occidental, central y a la URSS de manera directa a través de la ONU.

Hubo daños considerables a toda la infraestructura productiva sobre todo en transportes, edificios y terrenos de cultivo, además de escasez de materias primas y la industria que permaneció de pie contaba con maquinaria obsoleta. Existía gran inflación por la impresión de papel moneda y por el aumento de la deuda pública que los gobiernos de ambos bandos utilizaron para financiar los gastos de guerra: se estima que tan sólo en Estados Unidos los dólares en circulación había pasado de 65 a 222.5 mdd entre 1939 y 1946; y paradójicamente, Europa no podía importar productos norteamericanos por la escasez de dólares.

Sin embargo, fuera de Europa la guerra había algunos efectos positivos. La URSS, por ejemplo, logró ampliar su territorio y su esfera de influencia en Europa oriental; su zona asiática, tradicionalmente menos desarrollada que la zona Europea, se benefició por el traslado de la maquinaria industrial confiscada a Alemania. Otras regiones como Canadá, Oceanía, América Latina y Asia también vieron favorecidas sus industrias locales por el aumento de la producción de alimentos, materias primas y bienes manufacturados. El mundo tenía ahora un potencial productivo mayor debido al aumento de la producción de bienes de capital y al progreso de la ciencia y la tecnología.

Pero sin duda alguna fue en la economía de Estados Unidos donde la guerra tuvo los mayores efectos positivos. Estados Unidos logró una rápida reconversión hacia una economía de paz, pues en 1945 la mitad de la capacidad industrial se dedicaba a la producción bélica, pero tan sólo dos años después había culminado ya en gran medida la transición debido fundamentalmente a la adecuada planificación estatal, a los programas de formación profesional dirigidos al antiguo personal militar, al veloz incremento del consumo privado, a las inversiones en equipos e instalaciones y, finalmente, a la exportación de bienes y servicios organizada por el Estado. La economía norteamericana también se vio beneficiada por los siguientes elementos: el aumento del empleo de la mujer, el incremento de la producción de armamento por la carrera armamentista contra la URSS, el aumento de la productividad, el aumento de la producción de bienes de capital, y el desarrollo de la ciencia y la tecnología para usos civiles y militares. 
A diferencia de lo ocurrido al término de la primera guerra mundial, ahora los Estados Unidos asumieron de manera definitiva el papel de líder que les correspondía en el nuevo orden mundial geopolítico, económico y social. Esto significó un cambio hacia una política pronunciadamente internacionalista apoyándose para ello en la supremacía económica que había alcanzado, por la que el dólar se convertía en la divisa del comercio mundial y de los acuerdos internacionales. Con esta nueva política exterior los Estados Unidos dirigieron la creación de las instituciones que en materia serían las encargadas de la reconstrucción y el ordenamiento de las relaciones económicas internacionales: el Banco Mundial y el Fondo Monetario Internacional.

\section{El Plan Marshall}

A inicios de 1947 los países europeos tenían enormes déficits en sus balanzas de pagos, principalmente déficit comercial con Estados Unidos, lo que causaba una escasez de dólares que obligó a los países europeos a reducir drásticamente sus importaciones de bienes de capital procedentes de Estados Unidos, paralizando la reconstrucción. Así mismo, la "guerra fría" hizo aumentar el interés de Estados Unidos por una Europa económicamente sólida que pudiese actuar de contrapeso frente al expansionismo ruso soviético. Para hacer frente a estos dos problemas Estados Unidos anunció el 5 de junio de 1947 el Plan Marshall, ${ }^{39}$ cuyo objetivo central era ayudar a la reconstrucción de toda Europa.

El Plan Marshall contribuyó decisivamente a la renovación de las infraestructuras del transporte, a la modernización de las empresas agrarias e industriales, a la reanimación de la producción, el aumento de la productividad, a la dinamización de los intercambios comerciales intereuropeos, propició la recuperación del mercado monetario y de capitales de Londres, financió la recuperación del comercio mundial. En lo político, condujo a Europa hacia la sociedad de bienestar y al Estado social, ganando a Europa occidental como aliado de Estados Unidos. El Plan Marshall también fue definitivo en la reconstrucción acelerada de Alemania Occidental al impedir el desmontaje de la industria alemana sugerido por Francia, Rusia e Inglaterra.

\footnotetext{
${ }^{39}$ Para un resumen del Plan Marshall véase Bossuat (2008: 13-25).
} 


\section{Conclusión}

Con el New Deal había nacido el paradigma de la economía mixta inspirado en una visión keynesiana de la política económica en sustitución del paradigma liberal del laissez-faire. Al normalizarse la actividad económica después de la segunda guerra mundial se profundizó la intervención del Estado en los asuntos económicos, de tal manera que a finales de la década de 1940 el Estado era el mayor empresario en Francia, Italia y Gran Bretaña. El objetivo principal de la política económica sería de ahora en adelante el crecimiento económico y el pleno empleo, así surge la planeación y el seguimiento cuantitativo de las variables macroeconómicas, al tiempo que se crearon leyes de pleno empleo en Estados Unidos, Gran Bretaña y Suecia. Esto es el fundamento de lo que más tarde se llamaría Estado de Bienestar, que resultó de vital importancia para explicar el desempeño de la economía mundial a partir de la década de 1950, tema con el que iniciaremos un recorrido por la historia económica mundial hasta la década de 2000 en un próximo artículo.

\section{Bibliografía}

Ashworth, William (1978), Breve historia de la economía internacional desde 1850, Fondo de Cultura Económica, México.

Bossuat, Gerard (2008), The Marshall Plan: history and legalcy, en "The Marshall Plan: lessons learned for the $21^{\text {st }}$ century, Eliot Sorel y Pier Carlo Padoan (eds.), OECDm Paris, pp. 13-25.

Glade, William (2000), América Latina y la economía internacional, 18701914, en Historia de América Latina, 1870-1930, Leslie Bethell (ed.), Crítica, Barcelona, vol. 7, pp. 1-49.

Hardach, Gerd (1986), La Primera Guerra Mundial 1914-1918, Crítica, Barcelona. Colección Historia Económica Mundial del Siglo XX, vol. 2.

Hobsbawm, Eric (1998), La era del imperio (1875-1914), Labor Universitaria, Barcelona.

Keynes, J. M. (1923), Breve Tratado sobre la Reforma Monetaria, Fondo de Cultura Económica. México, 1992.

Keynes, J. M. (1925), Las consecuencias económicas del Sr. Churchill, en Ensayos sobre intervención y liberalismo, Editorial Orbis, Barcelona, 1986. 
Milward, Alan (1986), La Segunda Guerra Mundial 1939-1945, Crítica, Barcelona. Colección Historia Económica Mundial del Siglo XX, vol. 5.

Niveau, Maurice (1974), Historia de los hechos económicos contemporáneos, Ariel, Barcelona.

Rockoff, Hugh (1990), The "Wizard of Oz" as a monetary allegory, Journal of Political Economy, vol. 98, núm. 4, pp. 739-761.

Wee, Herman van der (1986), Prosperidad y crisis. Reconstrucción, crecimiento y cambio, 1945-1980, Crítica, Barcelona. Colección Historia Económica Mundial del Siglo XX, vol. 6. 